\title{
Indústria frigorífica: a voz do trabalhador entre a necessidade
}

\section{e a exaustão}

Isabel Cristina Rodrigues"

Gabriela Chaves Marra**

\section{Resumo}

Os processos produtivos tipicamente capitalistas têm mostrado efeitos adversos sobre as relações de trabalho estabelecidas na produção agropecuária, em especial pela imposição de jornadas excessivas, com graves consequências sobre a saúde do trabalhador. Fazem parte desse contexto as atividades de processamento e distribuição de carne realizadas pelos frigoríficos. Este artigo tem como objetivo geral verificar como os sentidos acerca do trabalho nesses espaços estão sendo produzidos pelos próprios trabalhadores. Para dar visibilidade a essas vozes, utilizamos o dispositivo de entrevistas, construídas a partir da articulação entre blocos temáticos de interesse, objetivos e problemas colocados pelas perguntas elaboradas, além da hipótese sobre possíveis respostas. As análises foram conduzidas da perspectiva teórica da Análise do Discurso, com ênfase em seus aspectos enunciativos, privilegiando-se o estudo de marcas linguísticas que indicavam a formação de um grupo e de um modo de enunciar específico, em relação recíproca, configurando assim dada prática discursiva.

Palavras-chave: Trabalhadores de frigorífico. Sentidos do trabalho. Análise do Discurso de base enunciativa. Prática discursiva.

\section{Introdução: breve panorama de questões de adoecimento relacionadas ao trabalho em frigoríficos}

Movimentos protagonizados por trabalhadores e sindicatos, ações do Ministério Público e produções acadêmicas vêm aprofundando o debate sobre a saúde dos trabalhadores de frigoríficos e denunciam uma conjuntura que leva a adoecimento, acidentes, afastamentos

\footnotetext{
Professora adjunta de Língua Portuguesa do Instituto de Aplicação da Universidade do Estado do Rio de Janeiro. Mestre em Letras pela UERJ e doutora em Estudos da Linguagem pela UFF, integra o GRPesq $\mathrm{CNPq}$ "Práticas de Linguagem, Trabalho e Formação Docente" e é pesquisadora colaboradora do GT ANPOLL "Discurso, Trabalho e Ética". Desenvolve pesquisas com ênfase nos seguintes temas: análise de discurso e estudos enunciativos; relação linguagem e trabalho; normas jurídicas, formação de professores e educação de surdos. E-mail: isabel060813@gmail.com

** Doutoranda em Saúde Pública pela Escola Nacional de Saúde Pública, Fiocruz. Graduada em Medicina Veterinária pela Universidade Federal Rural do Rio de Janeiro (2007) e mestrado em Saúde Pública pela Escola Nacional de Saúde Pública Sérgio Arouca (2014). E-mail: gabicmarra@uol.com.br
}

Data de submissão: ago. 2019 - Data de aceite: out. 2019 http://dx.doi.org/10.5335/rdes.v15i3.9616 
e aposentadorias por invalidez, além de descumprimento de normas de segurança em contraponto ao aumento da produtividade, visando ao lucro econômico. Os frigoríficos são parte da cadeia produtiva da carne, da qual fazem parte os produtores rurais e os varejistas. Essa cadeia inclui diversas etapas, que vão da produção de grãos para rações, como soja e milho, até a produção da carne processada, embalada e vendida no mercado.

O segmento responsável pelo abate e processamento da carne se constitui por um círculo restrito que controla o mercado internacional, tornando o setor de frigoríficos centralizado em poucas empresas de grande porte do agronegócio. Esse setor tem ampliado seu poder de deslocamento da margem lucro a seu favor, de modo cada vez mais financeirizado, submetendo-se aos interesses do capital e de empresários e explorando a força de trabalho. É fato que o agronegócio tem influência no cenário político e possui representatividade no Estado.

No Brasil, investimentos em tecnologia elevaram a produtividade e a qualidade do gado bovino, tornando-o competitivo e alcançando o mercado mundial. O país tem tradição na produção, industrialização e comércio dessa carne e possui o maior rebanho comercial. No entanto, o aumento do número de trabalhadores, assim como os determinantes da lucratividade de um frigorífico, tem impacto nos casos de adoecimentos e de acidentes.
Cabe lembrar que o modelo produtivo adotado nesse setor influenciou Henry Ford (1922/1926), quando visitou um abatedouro em Chicago, a elaborar o modelo de produção e organização do trabalho conhecido por fordismo. Ainda hoje, a organização do trabalho segue os pressupostos centrados nas metas de produção. Uma vez que o frigorífico esteja equipado e funcionando, quanto mais cabeças de gado e/ou aves abatidas por hora, menor será o custo de processamento de cada uma. O processo de trabalho se configura na forma de divisão - fragmentada, medida, padronizada e intensa, além de repetitiva, com uso constante de instrumentos perfurocortantes e manuseio de cargas pesadas. $\mathrm{O}$ ambiente é muitas vezes insalubre, não só pelas questões de biossegurança, mas também porque submete os trabalhadores a ruídos, má iluminação e extremos de temperatura e umidade, ocasionando diversos tipos de risco (PEREIRA, 2016; SILVEIRA, 2017).

Estudos atuais demonstram preocupação com a saúde do trabalhador de frigoríficos, tendo em vista tal processo produtivo. Na última década, observou-se a intensificação do trabalho, resultando em aumento de acidentes e de lesões, gerando absenteísmo e alta taxa de rotatividade, que se aproximou de 100\% (BOSI, 2013). Um estudo de Machado, Murofuse e Martins (2016) revela também as percepções de trabalhadores 
adoecidos mentalmente, em situações que, segundo os autores, foram tratadas pelos empregadores como subterfúgio para obter benefícios de afastamento ou aposentadoria.

A partir da necessidade no estabelecimento de limites às indústrias de processamento de carnes para a segurança e a saúde dos trabalhadores, em 2010, iniciou-se uma série de discussões entre sindicatos e Ministério Público, com a participação ativa da Confederação Nacional dos Trabalhadores das Indústrias da Alimentação (CNTA) e da Regional Latino-americana da União Internacional dos Trabalhadores da Alimentação (Rel-UITA). Como resultado desse processo, em 2013, o então Ministério do Trabalho publicou a Norma Regulamentadora $n^{\circ} 36$ (NR-36), sobre a saúde do trabalhador do setor de abate e processamento de produtos e subprodutos de carnes (BRASIL, 2013). A NR-36 é composta por 16 tópicos, com temas específicos como mobiliários e postos de trabalho, passarelas e plataformas, manuseio de produtos, levantamento de cargas, recepção e descarga de animais, além do estabelecimento de pausas para conforto térmico, entre outros (IKEDO; RUIZ, 2014).

Com base nessa contextualização, este artigo investiga, por meio de entrevistas, modos como o trabalhador do frigorífico, que faz parte diretamente de diferentes etapas produtivas (abate, desossa, cortes, inspeção de controle de qualidade etc.), aborda sua atividade profissional. Nas seções subsequentes, apresentamos o processo de construção da entrevista, a partir da discussão metodológica feita em Daher (2016), que se vale do conceito de gêneros de discurso (BAKHTIN, 1979/2011). Apresentamos, também, nossa perspectiva teórica, a saber, a Análise do Discurso de base enunciativa (doravante $\mathrm{AD}$ ), destacando como principal noção analítica a "prática discursiva", conforme proposta por Maingueneau (1993, 2005). Considerando essa perspectiva, expomos os resultados da entrevista, organizados em um corpus constituído a partir de marcas linguísticas que se mostraram recorrentes na fala dos trabalhadores, apontando para a formação de certo código linguageiro, noção também proposta por Maingueneau (1993, 2005).

Com tal pesquisa, pretendemos contribuir com a discussão acerca das relações entre linguagem e trabalho, a partir de uma perspectiva discursiva, apontando caminhos metodológicos par a abordagem de entrevistas. Assim, dando centralidade a saberes associados a um coletivo de trabalhadores (SOUZA-E-SILVA; FAÏTA, 2002), consideramos poder contribuir com uma dimensão ergológica de investigação, ao (re)estabelecer uma ligação entre atividades laborais, experiência humana e conhecimento. 


\section{Dispositivo teórico-} -metodológico: em direção a uma abordagem discursiva das percepções do trabalhador de frigorífico acerca de seu cotidiano profissional

Este artigo é uma parceria entre pesquisadoras das áreas da linguagem e da medicina veterinária, que visa a dar centralidade às práticas de linguagem no mundo do trabalho. Nouroudine (2002) considera que integram essas práticas três modalidades de relação entre trabalho e linguagem, propostas por Grant Johnson e Caplan (1979) e citadas por Lacoste (1995). Tal tripartição inclui a "linguagem sobre o trabalho", a "linguagem no trabalho" e a "linguagem como trabalho". Neste estudo, as entrevistas foram o dispositivo escolhido para acessar sentidos produzidos por um grupo de trabalhadores sobre seu cotidiano profissional. Ao dizer isso, gostaríamos de nos afastar de uma concepção de pesquisa como um desvelar de verdades, indo ao encontro do que diz Nouroudine (2002):

O duplo caráter dos conhecimentos produzidos, de alcance geral e marcados pela singularidade das situações, se traduz por uma humildade e uma abertura do pesquisador que impedem qualquer ideia de acabamento do saber acerca das atividades humanas. No prolongamento do princípio dialógico bakhtiniano, tal orientação epistemológi- ca leva a considerar o conhecimento das atividades humanas não como um estado a se atingir ou a se produzir, mas sempre como um processo a ser acionado e nunca inteiramente acabado (NOUROUDINE, 2002, p. 29).

Destacamos que o dialogismo (BAKHTIN, 1979/2011), a que alude Nouroudine, diz respeito à relação que cada enunciado mantém, obrigatoriamente, com outros enunciados. E não se trata somente da interação direta entre enunciadores, mas também de uma segunda articulação: a interação histórica que cada enunciado estabelece com todos os outros já existentes e com os ainda por vir. Assim, um enunciado é sempre, em menor ou em maior grau, uma resposta, em outras palavras: manifesta não só sua relação com o objeto temático do enunciado, mas também a relação do locutor com os enunciados de outros sobre esse mesmo objeto.

Ao destacar esse aspecto, já chamamos atenção para um primeiro procedimento de construção das entrevistas, que foi o da organização dos seguintes blocos temáticos: "ambiente de trabalho", "participação nas definições dos processos de trabalho" e "saúde no trabalho". Ao abordarem esses temas do cotidiano profissional, os trabalhadores põem em circulação uma série posicionamentos sobre eles. Mais do que descrever uma atividade, interpreta-se tal atividade em determinado espaço e tempo - reiterando-se assim a ideia de uma prática de linguagem sobre o trabalho. 
Daher (2016) destaca outro conceito caro aos estudos bakhtinianos, o dos gêneros do discurso, para discutir a construção do dispositivo de entrevista:

É certo que "cuidados metodológicos" têm sido apontados por diversos autores no que diz respeito à elaboração de um roteiro de entrevista. No entanto, em tais reflexões de ordem metodológica, não se encontram informações suficientes que garantam a construção de um roteiro com um status diferenciado do da mera conversação.

A esse respeito, parece ser de grande relevância a reflexão teórica de Bakhtin sobre a caracterização dos enunciados sob o ponto de vista dos gêneros do discurso. Partindo da distância verificada entre gêneros primários, também chamados simples, onde se incluem o diálogo cotidiano e a carta, e gêneros secundários (complexos), como seria o caso do romance, do teatro, do discurso científico e outros, o autor propõe novas bases para 0 tratamento dos enunciados em função de suas articulações genéricas. [...] Os gêneros primários, ao se tornarem componentes dos gêneros secundários, transformam-se dentro destes e adquirem uma característica particular: perdem sua relação imediata com a realidade existente e com a realidade dos enunciados alheios (BAKHTIN, 1992, p. 281).
A relação entre o que diz Bakhtin e as considerações anteriormente expostas, acerca do modo pelo qual o dispositivo "entrevista" é habitualmente considerado, aproximam-no do gênero secundário e não do primário (DAHER, 2016, p. 29-30).

\section{Ao enfatizar o caráter de gênero} secundário que deve ser atribuído à entrevista, já que esta se distancia de uma mera conversação, a autora chama atenção para a atividade científica em curso. A partir disso, propõe uma metodologia específica de organização desse instrumento, a saber: a reprodução dos passos seguidos pelos pesquisadores quando elaboram um projeto de pesquisa. Desse modo, ao lado de cada bloco temático, foram explicitados os objetivos a serem atingidos ao abordar cada um, os problemas que colocam para o pesquisador e as hipóteses que o norteiam, para posterior elaboração das perguntas, como descrito no Quadro 1.

Quadro 1 - Definição de etapas prévias à elaboração das perguntas da entrevista1

\begin{tabular}{|c|c|c|c|}
\hline Blocos temáticos & Objetivos & Problemas & Hipóteses \\
\hline $\begin{array}{l}\text { 1. Ambiente de } \\
\text { trabalho }\end{array}$ & $\begin{array}{l}\text { Observar modos de avalia- } \\
\text { ção dos trabalhadores de } \\
\text { suas condições de trabalho. }\end{array}$ & $\begin{array}{l}\text { Como os trabalhadores } \\
\text { compreendem o espaço } \\
\text { onde trabalham? }\end{array}$ & $\begin{array}{l}\text { Os trabalhadores } \\
\text { sentem-se submetidos a } \\
\text { condições precárias de } \\
\text { trabalho. }\end{array}$ \\
\hline $\begin{array}{l}\text { 2. Participação } \\
\text { nas definições } \\
\text { dos processos de } \\
\text { trabalho }\end{array}$ & $\begin{array}{l}\text { Reconhecer modos de } \\
\text { organização dos trabalha- } \\
\text { dores em relação aos pro- } \\
\text { cessos de trabalho. }\end{array}$ & $\begin{array}{l}\text { Os trabalhadores têm voz } \\
\text { na definição de encaminha- } \\
\text { mentos relacionados aos } \\
\text { processos de trabalho? }\end{array}$ & $\begin{array}{l}\text { A opinião dos traba- } \\
\text { lhadores acerca dos } \\
\text { processos de trabalho é } \\
\text { desconsiderada. }\end{array}$ \\
\hline $\begin{array}{l}\text { 3. Saúde } \\
\text { no trabalho }\end{array}$ & $\begin{array}{l}\text { Identificar percepções so- } \\
\text { bre os riscos e doenças re- } \\
\text { lacionados ao trabalho. }\end{array}$ & $\begin{array}{l}\text { Os trabalhadores estabe- } \\
\text { lecem relação entre as do- } \\
\text { enças e acidentes que os } \\
\text { acometem e os riscos a que } \\
\text { estão expostos? }\end{array}$ & $\begin{array}{l}\text { Os trabalhadores descon- } \\
\text { sideram a dimensão dos } \\
\text { riscos de suas atividades, } \\
\text { naturalizando-os. }\end{array}$ \\
\hline
\end{tabular}


As entrevistas foram realizadas no período de 12 a 22 de março de 2018 , com trabalhadores de dois frigoríficos registrados no Serviço de Inspeção Federal (SIF), um deles de bovinos e outro de aves, ambos localizados no município de Tangará da Serra, no estado do Mato Grosso. Tendo em vista a complexidade envolvida na aproximação com os trabalhadores por meio das empresas, o que pareceu deixá-los mais expostos e constrangidos pelo possível medo de perderem o emprego, a estratégia buscada foi a intermediação do Sindicato dos Trabalhadores nas Indústrias de Alimentação, Frigoríficas, de Álcool e de Refinação de Açúcar nos Municípios de Tangará da Serra e Região (Sintiaal), que se disponibilizou a fazer diretamente os convites.

Nove profissionais sindicalizados se dispuseram a participar das entrevistas, formando uma amostragem de tipicidade bastante conveniente no que diz respeito ao equilíbrio entre o número de informantes homens (4) e mulheres (5) e entre profissionais em atividade (6, sendo que um já esteve em licença) e afastados por motivo de doença (3). Em relação ao tipo de frigorífico, não foi possível manter equilíbrio na amostragem - o que acabou não se revelando um elemento de distinção na entrevista: 7 estavam vinculados ao trabalho com bois e 2 com aves. Há uma curva representativa da idade dos participantes, dos 26 aos 57 anos. O tempo de serviço dos entrevistados vai de 2 a 20 anos, observando-se um tempo médio de 9 anos de vinculação à indústria da carne.

$\mathrm{O}$ estudo garantiu o anonimato dos participantes (os nomes na tabela são fictícios) e respeitou todos os preceitos ético-legais que regem a pesquisa com seres humanos, tendo sido aprovado, em março de 2017, pela Comissão de Ética em Pesquisa da Escola Nacional de Saúde Pública da Fundação Oswaldo Cruz (CEP/Ensp/Fiocruz), o que está registrado no parecer $n^{\circ} 2.159 .239$. No Quadro 2, apresentamos a relação dos informantes, na mesma sequência de realização das entrevistas, e alguns de seus dados de interesse. Destaque-se que os informantes 6 e 7 - Jorge e Mauro - pediram para ser entrevistados ao mesmo tempo, no que foram atendidos. 


\begin{tabular}{|c|c|c|c|c|}
\hline $\begin{array}{l}\text { Informantes } \\
\text { na ordem das } \\
\text { entrevistas }\end{array}$ & Idade & $\begin{array}{l}\text { Situação } \\
\text { trabalhista }\end{array}$ & $\begin{array}{l}\text { Tipo de } \\
\text { frigorífico }\end{array}$ & Histórico de atribuições \\
\hline 1. Adelina & 40 & Em atividade & De bois & $\begin{array}{l}\text { Trabalhou na sala de abate por } 4 \text { anos. Há } 3 \text { anos } \\
\text { está no controle de qualidade, passando pelos seto- } \\
\text { res de desossa, abate e miúdos. }\end{array}$ \\
\hline 2. Janice & 38 & Afastada & De frango & $\begin{array}{l}\text { Trabalhou na sala de abate, fazendo evisceração, e } \\
\text { na sala de corte por } 3 \text { anos. Está afastada há } 4 \text { me- } \\
\text { ses com bursite nos dois ombros e túnel do carpo no } \\
\text { punho direito. }\end{array}$ \\
\hline 3. Joana & 42 & Afastada & De bois & $\begin{array}{l}\text { Começou a trabalhar em 2003, na desossa. Está } \\
\text { afastada há } 7 \text { anos. Fez cirurgia nas mãos. }\end{array}$ \\
\hline 4. Clara & 36 & Afastada & De bois & $\begin{array}{l}\text { Trabalhou na desossa de } 2009 \text { a } 2011 \text { e de } 2012 \text { a } \\
\text { 2014. Está afastada pela segunda; desta vez, há } 4 \\
\text { anos. Tem bursite nos dois ombros e fez cirurgia no } \\
\text { joelho e coluna. }\end{array}$ \\
\hline 5. Sônia & 46 & Em atividade & De frango & $\begin{array}{l}\text { Trabalha há } 7 \text { anos na desossa. Afastou-se por } 4 \\
\text { meses com dores nos ombros e foi liberada para } \\
\text { trabalhar. Está com perícia marcada. }\end{array}$ \\
\hline 6. Jorge & 57 & Em atividade & De bois & $\begin{array}{l}\text { Trabalha há } 20 \text { anos. Começou no abate e, atual- } \\
\text { mente, está na triparia. }\end{array}$ \\
\hline 7. Mauro & 26 & Em atividade & De bois & Trabalha há 2 anos na desossa. \\
\hline 8. Paulo & 39 & Em atividade & De bois & $\begin{array}{l}\text { Trabalha há } 13 \text { anos, de } 2005 \text { a } 2010 \text { no abate; } \\
\text { desde 2011, na desossa. }\end{array}$ \\
\hline 9. Júlio & 31 & Em atividade & De bois & $\begin{array}{l}\text { Trabalha há } 6 \text { anos; começou no abate e, atualmen- } \\
\text { te, está na desossa. }\end{array}$ \\
\hline
\end{tabular}

Em uma abordagem semiestruturada, que deixasse os trabalhadores o mais à vontade possível para construir suas respostas, a médica veterinária, pesquisadora que conduziu as entrevistas, propôs as seguintes perguntas de base:

- bloco temático 1 - "Em qual área do frigorífico trabalha e como é o trabalho nessa área?", "Como começou a trabalhar no frigorífico?", "Como é ser mulher e trabalhar no frigorífico? [no caso das mulheres]";
- bloco temático 2 - "Como são as relações entre os trabalhadores?", "Há algum tipo de pressão no trabalho?";

- bloco temático 3 - "Há algum risco de acidente na área onde trabalha? Quais?", "Por que se afastou? [no caso de trabalhador em licença]".

As perguntas não foram feitas, necessariamente, nessa sequência, procurando atender ao próprio caminho da fala do entrevistado. A pesquisadora percebeu bastante dificuldade/receio, 
entre a maioria deles, em discorrer sobre as perguntas de modo mais detalhado, $o$ que levou a reformulações das perguntas a partir de respostas mais breves já dadas. $\mathrm{O}$ conjunto das entrevistas pode ser consultado em Marra (2019).

Conforme assinalamos na seção anterior, o objetivo das entrevistas era investigar modos como o trabalhador do frigorífico aborda sua atividade profissional, tendo em vista a contextualização exposta, que descreve um cenário de adoecimento nessa indústria. A partir da perspectiva teórica da $\mathrm{AD}$ de base enunciativa, tomamos o conceito de "prática discursiva", proposto por Maingueneau (1993, 2005), como a noção analítica de base.

A $\mathrm{AD}$ que praticamos tem por base uma concepção de língua que, apenas no encontro com a história, produz sentidos, afastando-se assim da compreensão de língua como sistema de comunicação, como um instrumento transparente, que apenas veicula informações.

É a própria noção de "comunicação linguística" que, desta forma, é deslocada: o fato de que um enunciado supõe um enunciador, um destinatário, uma relação com outras enunciações reais ou virtuais, que esteja atravessado pelo implícito, etc.; tudo isso não é uma dimensão que se acrescentaria posteriormente a uma estrutura linguística já constituída, mas algo que condiciona radicalmente a organização da língua. (MAINGUENEAU, 1993, p. 20-21).

O reconhecimento dessa complexidade de elementos em funcionamento vai ao encontro da perspectiva bakhtiniana citada anteriormente: há uma dimensão social da língua, que é constitutiva. Para Maingueneau (1993), trata-se de uma relação de imbricação: grupos e seus enunciados se constituem mutuamente. Não se trata de uma relação de anterioridade - um grupo se forma e cria os enunciados que o caracterizam - nem de adesão - cada um "escolhe" os enunciados que lhe interessam: "a instituição discursiva possui, de alguma forma, duas faces, uma que diz respeito ao social e outra, à linguagem" (MAINGUENEAU, 1993, p. 55). Desse modo, grupos dão sustentação a enunciados na mesma medida em que tais enunciados sustentam tais grupos. $\mathrm{O}$ autor propõe que essa imbricação seja compreendida em termos de uma "prática discursiva":

[...] falaremos de prática discursiva para designar esta reversibilidade essencial entre as duas faces, social e textual, do discurso. Assim procedendo, reformulamos um termo de Michel Foucault, que o utiliza para referir-se ao sistema que, no interior de uma formação discursiva dada, regula a dispersão dos lugares institucionais passíveis de serem ocupados por um sujeito de enunciação. Aqui ver-se-á, de preferência, um processo de organização que estrutura ao mesmo tempo as duas vertentes do discurso. A noção de "prática discursiva" integra, pois, esses dois elementos: por um lado, a formação discursiva, por outro, o que chamaremos de comunidade discursiva, isto é, o grupo ou a organização de grupos no interior dos quais são produzidos, gerados os textos que dependem da formação discursiva. A "comunidade discursiva" não deve ser entendida de forma excessivamente restritiva: ela não 
remete unicamente aos grupos (instituições e relações entre agentes, mas a tudo que esses grupos implicam no plano da organização material e no modo de vida). [...] É preciso ainda deixar bem claro que visamos aqui aos grupos que existem unicamente por e na enunciação, na gestão destes textos, e não aos grupos que encontrariam sua razão de ser em outro lugar; [destaques do autor] (MAINGUENEAU, 1993, p. 56).

A partir do exposto, ressaltamos dois pontos relacionados à pesquisa:

(i) investigar os modos como o trabalhador de frigorífico aborda seu cotidiano profissional significa, neste artigo, procurar descrever uma dada prática discursiva;

(ii) descrever uma prática discursiva leva à delimitação de uma comunidade discursiva, formada pela sustentação de certos textos (e sentidos) comuns, e não por critérios outros de pertencimento (por exemplo, geográfico ou institucional).

Portanto, para além da aparente dispersão ou da aparente homogeneidade de características extralinguísticas, trata-se de um tipo de investigação que visa a discriminar elementos que constituam efetivamente uma comunidade de discurso. De outro modo, podemos dizer: todos os entrevistados trabalham em frigoríficos de uma mesma região do país, todos pertencem a um mesmo sindicato, mas nos cabe analisar se os sentidos que se depreendem de suas falas apontam para essa mesma homogeneidade do pon- to de vista discursivo - e se tais sentidos, por sua vez, aproximam-se do que vem sendo abordado nos atuais estudos sobre suas condições de trabalho.

Antes de passar aos resultados, cabe destacar, por fim, uma segunda noção proposta por Maingueneau, que orientou a análise das falas - a de código linguageiro. Uma prática discursiva acaba por configurar um conjunto de regras, responsável pelo que pode/deve ser dito, apontando para determinado modo de apropriação da linguagem socialmente constituído. Segundo o autor, o código linguageiro diz respeito à "maneira pela qual é necessário enunciar, pois é a única conforme ao universo de sentido que ele [o discurso] instaura [destaque do autor]" (MAINGUENEAU, 1998, p. 22).

Desse modo, não foi o texto das entrevistas em sua linearidade que nos permitiu reconhecer uma comunidade discursiva entre os trabalhadores: foi a recorrência de determinadas marcas linguísticas que apontou para certo código linguageiro, ou seja, para certo modo de dizer constitutivo desse grupo. Essas marcas linguísticas permitiram a organização de um corpus de análise. Assim, como se verá adiante, não se tratava mais do conjunto das entrevistas em si, mas sim de um conjunto de enunciados delimitados, produzindo certos sentidos coletivos acerca do ambiente de trabalho, da participação nos processos de trabalho e da saúde no 
trabalho em determinados frigoríficos brasileiros.

\section{A voz do trabalhador:} sobre o excesso, sobre a frequente vigilância e sobre o reconhecimento da vigência da lei

Conforme expusemos na seção anterior, foi possível reconhecer algumas marcas linguísticas recorrentes nos enunciados dos trabalhadores, configurando uma dada prática discursiva. Elegemos seis dessas marcas, apresentadas nas subseções a seguir, com base em dois critérios:

(i) a associação com os blocos temáticos que orientaram o planejamento das perguntas;

(ii) a recorrência com que são empregadas pelos nove entrevistados.

Recortamos, em cada uma das entrevistas, identificadas por números de $1 \mathrm{a}$ 9 , todas as sequências discursivas (SD) nas quais há ocorrência das marcas de interesse. São várias sequências por entrevista, ainda que as nove sejam relativamente curtas. As sequências foram identificadas pelas letras minúsculas do alfabeto. Em seguida, agrupamos as SD em quadros, de modo que a recorrência de uma mesma marca pode ser consultada por bloco temático e por entrevista. Como esse corpus contém ao todo cerca de 30 quadros, selecionamos, a título de exemplo, na análise de cada bloco temático, sempre a primeira SD de cada entrevista. Assim, "SD1.a" é a sequência discursiva da entrevista 1 contendo a primeira ocorrência da marca linguística em questão; "SD2.a", a sequência discursiva da entrevista 2 contendo a primeira ocorrência da marca linguística em questão; e assim sucessivamente. A íntegra dos quadros com os conjuntos de SD pode ser consultada em Marra (2019).

\section{Bloco temático 1: ambiente de trabalho}

A literatura acadêmica registra, como mostramos na seção introdutória, que o trabalho na indústria frigorífica se caracteriza pela sobrecarga em diferentes aspectos: o peso do produto manipulado, a repetição de movimentos, a insalubridade do ambiente, a periculosidade dos instrumentos utilizados, a extensão do tempo destinado a atividades marcadas pelos aspectos anteriores. Nesse sentido, nossa expectativa era a de que os trabalhadores, durante a entrevista, ao tematizarem seu "ambiente de trabalho", descreveriam um contexto de condições precárias. Nossa análise não confirmou essa hipótese tal qual a formulamos, pois não se trata exatamente de precariedade, mas sim de excesso, aquilo que se depreendeu da fala dos trabalhadores. 
Nesse primeiro bloco temático, duas marcas linguísticas se destacaram nas entrevistas: o uso de palavras intensificadoras e o de palavras de quantificação indefinida, como "muito", "mais", "tudo", "vários", dentre outras expressões ou estruturas de significado equivalente no contexto. Em linhas gerais, os funcionários dos frigoríficos não relatam apenas que "trabalham" ou que "as condições de trabalho são difíceis". De forma sintética, pode-se dizer que eles relatam que "trabalham muito" e que "as condições são muito difíceis", em seus mais diversos aspectos. Há uma percepção dos trabalhadores de um ambiente de trabalho que age sobre o corpo pressionando-os para o limite de suas condições físicas e emocionais ${ }^{2}$ - percepção articulada na materialidade linguística pelo uso, nas respostas da entrevista, de palavras intensificadoras e de quantificação indefinida.

Tais marcas, neste bloco temático, parecem procurar reproduzir o que se chama de mundo real. A sobrecarga na atividade realizada se faz representar nesse modo de enunciar específico, que atravessa as falas dessa população de trabalhadores, como indicam as sequências discursivas do Quadro 3. Assim, em termos discursivos, ao abordar sua atividade, nota-se que os entrevistados necessariamente precisam "enunciar" todos os excessos a que se sentem submetidos.
Quadro 3 - Sequências discursivas associadas ao bloco temático 1 da entrevista

\begin{tabular}{|c|c|}
\hline SD & $\begin{array}{c}\text { Exemplos de ocorrência de marcas } \\
\text { linguísticas de intensificação ou de } \\
\text { quantificação indefinida }\end{array}$ \\
\hline 1.a & $\begin{array}{l}\text { então não é esforço físico, mas é esforço } \\
\text { mental, tem que ter muita responsabilidade }\end{array}$ \\
\hline 2.a & $\begin{array}{l}\text { na sala de corte eu fazia tudo que tinha } \\
\text { lá dentro }\end{array}$ \\
\hline 3.a & $\begin{array}{l}\text { é muito frio lá dentro e dói tudo o corpo da } \\
\text { gente, começa a me inchar toda }\end{array}$ \\
\hline 4.a & eu trabalhei muito, pegava muito peso \\
\hline $5 . a$ & $\begin{array}{l}\text { Quando vai fazer vistoria lá, eles vão, } \\
\text { bota para rodar devagarinho [a linha } \\
\text { de produção], pouquinho né (...) mas } \\
\text { quando a pessoa sai, ah minha filha, é } \\
\text { no correndo, é rápido, ali, tem tempo que } \\
\text { fazia picanha sozinha }\end{array}$ \\
\hline 6/7.a & $\begin{array}{l}\text { Tem [risco], porque querendo ou não lá na } \\
\text { desossa é uma distância assim [indicação } \\
\text { de tamanho bem pequeno] do outro, então } \\
\text { um tá desossando, o outro também }\end{array}$ \\
\hline 8.a & $\begin{array}{l}\text { [na pistola] mexe com boi vivo, tem que } \\
\text { ter cuidado, porque é bem perigoso (...) é } \\
\text { bem perigoso }\end{array}$ \\
\hline 9.a & $\begin{array}{l}\text { tu lida direto com a morte, (...) } \\
\text { desgastante, bem desgastante, porque tá } \\
\text { ali o dia inteiro, dependendo do número } \\
\text { de animais, as vezes vai o dia inteiro, é } \\
\text { calor, um dia como hoje, deus me livre, } \\
\text { muito calor }\end{array}$ \\
\hline
\end{tabular}

\section{Bloco temático 2: participação} nas definições dos processos de trabalho

Seguindo os critérios (i) e (ii), apresentados no início desta terceira seção, observamos que, ao tematizar os processos de trabalho, os entrevistados descreviam uma hierarquia constante de controle, mais uma vez por meio de duas marcas: designações claras de cargos superiores e elementos impessoais. As- 
sim, ao remeterem a níveis hierárquicos superiores, os trabalhadores não só se referiam a "encarregados" (pelos funcionários), a "supervisores" (do trabalho), a "técnicos de segurança", à "empresa", como também a "eles", sem referente claro (de quem exatamente se trata?), ou a ações verbais em terceira pessoa do plural - também sem referentes claros de seus agentes.

Por meio da recorrência dessas marcas, observa-se que os trabalhadores indicam com regularidade a presença de um tipo de inspeção que garantiria o andamento das atividades no ritmo desejado - ritmo percebido como muito rápido, muito pesado, conforme exposto no bloco temático 1. Até mesmo nos momentos de complicações de saúde, o trabalhador é interpelado a voltar ao ritmo.

Essa inspeção/controle, como salientamos, nem sempre é claramente identificada. Pode-se considerar, em um nível mais superficial, que essa referência vazia em terceira pessoa do plural é apenas um tipo de informalidade - afinal, todos sabem que se fala de um superior. Porém, ainda que se possa supor que se esteja falando de encarregados, supervisores, dos próprios empregadores, é preciso lembrar que os trabalhadores estão conversando, no momento da entrevista, com uma pesquisadora, que, a rigor, desconhece as relações cotidianas do ambiente de trabalho. Uma marca linguística recorrente como essa, estru- turadora de um conjunto de enunciados como os analisados, parece apontar para o fato de que os trabalhadores se sentem "olhados" todo o tempo, "vigiados", como por um "panóptico" (FOUCAULT, 1975/2014), portanto sempre com certa impessoalidade. Não importa assim quem especificamente assume a terceira pessoa. Na organização do ambiente de trabalho, há sempre um elemento em nível hierárquico superior que faz cumprir ou procura fazer cumprir regras, que vão das medidas de segurança, o que é um benefício, à sempre obrigatória rapidez na execução das tarefas - o que é relatado como opressão.

Desse modo, em relação à hipótese que formulamos para esse bloco temático, os enunciados apontam bem mais para um lugar de silenciamento do que de participação no que diz respeito aos processos de trabalho. Mesmo quando um trabalhador critica outro trabalhador, quando, por exemplo, não atende a uma norma de segurança, observa-se que há um relato repetido de desvinculação entre trabalhador da linha de produção e o que desejam seus superiores. 
Quadro 4 - Sequências discursivas associadas ao bloco temático 2 da entrevista ${ }^{3}$

\begin{tabular}{|c|c|}
\hline SD & $\begin{array}{l}\text { Exemplos de ocorrência de marcas } \\
\text { linguísticas de designação ou de } \\
\text { impessoalidade }\end{array}$ \\
\hline 1.a & $\begin{array}{l}\text { Tem risco, mas é tudo... eles [os } \\
\text { trabalhadores que lidam diretamente com } \\
\text { a carne] usam luva, luva de aço, colete de } \\
\text { aço também, tem umas áreas que precisa } \\
\text { usar, o técnico de segurança tá sempre } \\
\text { fazendo visita pra ver se o pessoal tá } \\
\text { usando, protetor auricular. }\end{array}$ \\
\hline 2.a & $\begin{array}{l}\text { Eles [possivelmente os empresários] têm } \\
\text { toda uma lei que já deviam estar cumprindo }\end{array}$ \\
\hline 3.a & $\begin{array}{l}\text { Agora tô de INSS, tive que voltar, aí voltei, } \\
\text { trabalhei uns } 15 \text { dias e não aguentei, é } \\
\text { porque é muito frio lá dentro (...) aí eu pedi } \\
\text { pra eles me trocar de setor, mas aí eles } \\
\text { não quiseram, aí eu tive que voltar pro } \\
\text { INSS de novo. }\end{array}$ \\
\hline 4.a & $\begin{array}{l}\text { as pessoas [os trabalhadores] mesmo que } \\
\text { tinham que cuidar, né, eu penso assim, } \\
\text { porque se a empresa tá dando as luvas, } \\
\text { tá dando tudo certinho, acho que a pessoa } \\
\text { tinha que usar direito }\end{array}$ \\
\hline 5.a & $\begin{array}{l}\text { a gente não pode ser devagar tem que ser } \\
\text { rápido, né, porque senão arroia e tem que } \\
\text { parar, e aí eles briga, né chega na gente e } \\
\text { chama atenção }\end{array}$ \\
\hline 6/7.a & $\begin{array}{l}\text { Tem muitos [trabalhadores] que se afastam } \\
\text { devido a pressão psicológica por parte dos } \\
\text { supervisores, encarregados de cumprir a } \\
\text { meta, velocidade. }\end{array}$ \\
\hline 8 & Sem ocorrências. \\
\hline 9 & Sem ocorrências. \\
\hline
\end{tabular}

\section{Bloco temático 3: saúde no trabalho}

Em relação ao último bloco temático, a expectativa da pesquisa era a de que os trabalhadores desconsiderassem a dimensão dos riscos de suas atividades, naturalizando-os, o que não se confirmou. Em vários momentos, os trabalhadores deixaram clara sua percepção dos riscos envolvidos em suas atividades, em especial devido ao tópico abordado no bloco temático 1 . No entanto, destacamos aqui duas novas marcas linguísticas que atravessaram todas as entrevistas, indicando uma mudança, para melhor, no ambiente de trabalho, com efeitos claros sobre a saúde física e emocional dos funcionários. Essas marcas se configuram por uma conjugação de dêiticos temporais em confronto ou por verbos indicando tempos também em confronto. Assim, referências temporais, como "hoje", "agora", "depois", contrapunham-se a "antes", "antigamente", "na época”, "no começo", indicando que condições de trabalho se modificaram. Por sua vez, verbos como "mudou" e "melhorou", ou outros como "ter", "fazer" no pretérito imperfeito do indicativo e na forma negativa e logo em seguida no presente do indicativo e na forma afirmativa ("não tinha"/"tem", "não fazia"/"faz"), apontavam para o mesmo contexto de alteração de uma dada realidade ao longo do tempo. Apenas duas entrevistas não fazem explicitamente esse tipo de menção, o que nos faz considerar tais marcas como mais um processo enunciativo característico dessa comunidade - de outro modo, como mais um código linguageiro que configura essa comunidade discursiva.

Avaliamos que essas referências só podem ser motivadas pelo dispositivo legal constituído pela NR-36 do então 
Ministério do Trabalho, extinto em 2019, que chega a ser explicitamente tematizada por um dos entrevistados. A mudança relatada aponta para condições de trabalho mais seguras e mais humanizadoras, na medida em que parecem mitigar o desgaste e o sofrimento decorrentes do "excesso" relatado. E a ideia de apenas "mitigar" se confirma em enunciados como o exposto na SD6/7.b: "a gente trabalhava 12 [horas] em ambiente frio, não tinha pausa térmica, a gente sofria mais" - ou seja, sofre-se menos, mas não se deixou de sofrer. A caracterização de um trabalho que funciona na fronteira da exaustão física e psíquica permanece presente, ainda que a norma reguladora tenha significado grande avanço, conforme exposto no texto de apresentação de Brasil (2017):

A Norma Regulamentadora n⿳ 36 - Segurança e Saúde no Trabalho em Empresas de Abate e Processamento de Carnes e Derivados (NR-36), publicada pela Portaria n. ${ }^{\circ} 555$, de 18 de abril de 2013 , representa a realização de um esforço de, pelo menos, uma década, do Ministério do Trabalho, além da Fundacentro, do Ministério Público do Trabalho, de trabalhadores e de empregadores, com o intuito de fomentar condições seguras e saudáveis nesse ramo de atividade.

O Brasil se orgulha de ser um país dinâmico e eficiente na agroindústria, e as empresas de processamento de carnes têm recebido grande destaque na produção de divisas para o país. Esta pujança econômica não pode se dar, entretanto, às custas da insegurança, desconforto e deterioração da saúde dos trabalhadores.
Com a implementação da NR-36, este setor poderá se tornar não apenas exemplo de produtividade, mas também de valorização e de promoção da qualidade de vida de seus trabalhadores. O presente Manual de Aplicação atende de forma contundente aos princípios de publicidade e transparência estabelecidos na legislação brasileira, que determina que sejam elaborados mecanismos facilitadores da implementação da legislação, que aportem conhecimento, maior compreensão e clareza aos atos normativos, especialmente para aqueles que devem exigi-la.

Assim, em relação à hipótese inicialmente formulada na pesquisa, surpreendeu-nos a clara percepção do trabalhador acerca das mudanças no ambiente do trabalho, e também nos processos de trabalho, voltadas para o benefício de sua saúde.

Quadro 5 - Sequências discursivas associadas ao bloco temático 3 da entrevista

\begin{tabular}{|c|c|}
\hline SD & $\begin{array}{l}\text { Exemplos de ocorrência de marcas } \\
\text { linguísticas temporais indicadoras de } \\
\text { mudança de contexto }\end{array}$ \\
\hline 1.a & $\begin{array}{l}\text { A empresa ali... mudou muita coisa, } \\
\text { melhorou bastante, hoje eles vê mais } \\
\text {.. tem o sindicato que apoia a gente, } \\
\text { melhorou bastante, mas antes eles não } \\
\text { valorizavam muito }\end{array}$ \\
\hline 2.a & $\begin{array}{l}\text { Não há ocorrência das marcas que } \\
\text { indicam mudanças no ambiente, mas } \\
\text { alude-se à existência de uma lei que, } \\
\text { para este entrevistado, não está sendo } \\
\text { cumprida: } \\
\text { "Eles têm toda uma lei que já deviam } \\
\text { estar cumprindo, que é a lei de dar uma } \\
\text { paradinha, uma ginástica laboral, isso eu } \\
\text { não vi acontecer lá na empresa". } \\
\text { Cabe destacar que esse entrevistado } \\
\text { está há apenas } 3 \text { anos na empresa, o que } \\
\text { pode explicar que ele se refira ao seguinte } \\
\text { contexto como habitual, enquanto outros } \\
\text { o tomam como conquista recente: } \\
\text { "tem descanso térmico, são três } \\
\text { descansos térmicos que a gente tem, } \\
\text { dois na parte da manhã e um de tarde". }\end{array}$ \\
\hline
\end{tabular}


(cont.)

\begin{tabular}{|c|c|}
\hline 3.a & $\begin{array}{l}\text { Com certeza, [tem] muito [risco dentro do } \\
\text { frigorífico]. Agora não, eles estão usando } \\
\text { muito coisa tipo luva, coisa, mas antes } \\
\text { a gente não usava nada disso. Aquela } \\
\text { proteção no corpo da gente, no braço, } \\
\text { na mão. Mas antigamente a gente não } \\
\text { usava, mas agora tá usando. }\end{array}$ \\
\hline 4.a & $\begin{array}{l}\text { a gente fazia muita hora [extra], depois } \\
\text { não porque foi proibido, né, mas no } \\
\text { começo a gente fazia até } 4 \text { horas extra. }\end{array}$ \\
\hline 5.a & agora tem umas cadeiras lá \\
\hline 6/7.a & $\begin{array}{l}\text { Antigamente era na mão, sem precisar } \\
\text { serrar, hoje tira o espinhaço para } \\
\text { desossar. } \\
\text { Observação: nesta entrevista, marca- } \\
\text { se explicitamente o conhecimento da } \\
\text { existência de norma legal específica: } \\
\text { "outra coisa que eu vejo também, que eu } \\
\text { penso, com essa NR-36 do frigorífico". }\end{array}$ \\
\hline 8.a & $\begin{array}{l}\text { Nesta entrevista, apesar de se tratar } \\
\text { de um trabalhador com } 20 \text { anos de } \\
\text { frigorífico, não há indicação de mudança } \\
\text { no ambiente de trabalho, ainda que } \\
\text { haja uma referência aos intervalos de } \\
\text { descanso, mas sem que se indique, } \\
\text { como a maioria o faz, que se trata de algo } \\
\text { conquistado recentemente: } \\
\text { "a hora que tá matando [os animais], tem } \\
\text { as paradas, a cada } 1 \text { hora, para } 10,15 \\
\text { minutos, dá pra descansar". }\end{array}$ \\
\hline 9.a & $\begin{array}{l}\text { Hoje não acontece tantos, hoje tem } \\
\text { muita segurança, entendeu, hoje a gente } \\
\text { trabalha com cinto de segurança nas } \\
\text { plataformas alta, trabalha com luvas de } \\
\text { segurança, hoje é bem raro um caso de } \\
\text { acidente, a não ser claro, um desmaio, } \\
\text { mas acidente não, muito difícil }\end{array}$ \\
\hline
\end{tabular}

No Quadro 6, apresentamos uma síntese das marcas linguísticas depreendidas a partir da fala dos trabalhadores dos frigoríficos durante as entrevistas. De acordo com nossa análise, essas marcas, em uma perspectiva discursiva, constroem certo código linguageiro, ou seja, um modo de enunciar necessário para que determinados sentidos se produzam.
Quadro 6 - Marcas linguísticas associadas a um código linguageiro

\begin{tabular}{|c|c|c|}
\hline $\begin{array}{c}\text { Blocos } \\
\text { temáticos }\end{array}$ & $\begin{array}{l}\text { Marcas linguísticas } \\
\text { recorrentes nas } \\
\text { entrevistas }\end{array}$ & Sentidos produzidos \\
\hline 1 & $\begin{array}{l}\text { Palavras intensifica- } \\
\text { doras } \\
\text { Palavras de quantifi- } \\
\text { cação indefinida }\end{array}$ & $\begin{array}{l}\text { Excessos subme- } \\
\text { tidos ao corpo, em } \\
\text { seus aspectos físi- } \\
\text { cos e emocionais, } \\
\text { pelas atividades } \\
\text { exercidas pelos } \\
\text { trabalhadores }\end{array}$ \\
\hline 2 & $\begin{array}{l}\text { Designações relacio- } \\
\text { nadas aos cargos } \\
\text { ocupados pelos supe- } \\
\text { riores aos trabalhado- } \\
\text { res entrevistados } \\
\text { Referências impes- } \\
\text { soais (pronome "eles" } \\
\text { sem referente e ora- } \\
\text { ções com sujeito in- } \\
\text { determinado) a esses } \\
\text { mesmos superiores }\end{array}$ & $\begin{array}{l}\text { Constante vigilân- } \\
\text { cia dos trabalhado- } \\
\text { res no exercício de } \\
\text { suas atividades }\end{array}$ \\
\hline 3 & $\begin{array}{l}\text { Dêiticos temporais } \\
\text { confrontando passa- } \\
\text { do e presente } \\
\text { Verbos também } \\
\text { confrontado passado } \\
\text { e presente }\end{array}$ & $\begin{array}{l}\text { Transformação de } \\
\text { um ambiente de } \\
\text { trabalho inóspito } \\
\text { para um contexto } \\
\text { mais humanizado }\end{array}$ \\
\hline
\end{tabular}

\section{Considerações finais}

Nosso percurso até aqui foi o de discriminar uma prática discursiva a partir da análise de entrevistas. Tal prática, segundo procuramos apresentar na seção anterior, evidenciou três sentidos fundamentais ao abordar o cotidiano do trabalho em frigoríficos: os sentidos do excesso, do controle e da mudança - os três correlacionados a certo código linguageiro, evidenciado por marcas linguísticas específicas. Como se pôde observar, há aproximações entre esses 
resultados e outras reflexões acadêmicas que vêm sendo produzidas sobre o trabalho na indústria da carne. Uma indagação que consideramos relevante é: seria possível alguma forma de ação que viabilizasse condições cada vez mais dignas para os trabalhadores dessa indústria, tendo em vista o conhecimento produzido? É uma interface a se fortalecer entre a produção de conhecimento na área das humanidades e o mundo do trabalho. A seguir, indicamos alguns aspectos que nos parecem importantes de serem também aprofundados.

No conjunto das entrevistas, não são denunciadas condições precárias de trabalho; ao contrário, os relatos enfatizam melhoria de condições. Esse é um aspecto importante, já que sinaliza o reconhecimento da vigência de uma lei. Há um senso comum que reitera que leis no Brasil não são devidamente respeitadas. No caso da NR-36, observa-se que ela nasce de debates em que se articularam governo e trabalhadores, promovendo benefícios. $\mathrm{E}$, mesmo na percepção de um cotidiano de controle hierárquico ostensivo, muitas vezes redutor da voz do trabalhador, também se enfatiza um dado positivo, relacionado a essa norma: a atenção com a segurança do trabalhador no desempenho de sua atividade. Que fatores contribuíram para que essa lei "pegasse", como parece ser o caso?

A despeito disso, porém, ainda está presente a referência constante a formas de exaustão, física e psíquica. O excesso apontado parece intimamente relacionado ao contexto de uma intensa cadeia produtiva voltada para o consumo, nacional e internacional, como a literatura da área já aponta. E o quadro dos entrevistados sugere que essa exaustão parece afetar sobretudo mulheres, pois são elas, dentre os informantes desta pesquisa, que estão em afastamento. É uma questão a se investigar. Um dilema complexo que gostaríamos de destacar, e que parece associado ao contexto de exaustão dos trabalhadores, é o fato de que não só precisam produzir muito, mas de que também precisam manipular extensamente outras espécies de vida animal. Parecem sintetizar esse dilema os seguintes trechos das entrevistas $1 \mathrm{e}$ 8 , respectivamente:

Como é trabalhar na área de atordoamento?

(...) Eles [os bois] ficam no curral, depois são mandados pra seringa, tem um choquinho pra estimular eles a entrarem, toma na cabeça e fica atordoado, não vai sentir, aí levanta e degola ele.

O que você acha desse trabalho, da pistola e sangria?

Normal, às vezes fico lá, é meu serviço também inspecionar, ver se dá tempo de um cair e outro levantar, às vezes eu vejo assim aquela frieza, são muitos animais. 


\section{Como é matar o boi?}

Eles usam uma pistola lá que vai na cabeça dele lá, e o boi cai, nem morre direito, não tempo, é rápido demais, tem vezes que vai 120 bois por hora, não dá tempo né, é bem corrido.

\section{O senhor trabalharia nessa função?}

Ah, não tenho coragem, nem na marreta nem na sangria, tenho coragem não. É muito bicho, hoje mesmo foram mais de 1300 animais.

De quanto de frieza e de coragem se precisa para realizar essa atividade? Qual duração da jornada de trabalho e do tempo de serviço impediria que esses sentimentos se esgotassem no trabalhador? Considerações para trabalhos futuros.

\section{Slaughterhouse industry: the worker's voice between need and exhaustion}

\section{Abstract}

The capitalist productive processes have shown adverse effects on the labor relations established in agricultural production, especially due to the imposition of excessive hours that bring serious consequences to the workers' health. This context includes meat processing and distribution carried out by the slaughterhouses. This paper aims at checking how the meanings that circulate around the work in those places are being produced by the workers themselves.
In order to make those voices heard, we used interviews, which were built from the articulation between topics of interests, objectives and problems organized in blocks as questions and hypotheses of possible answers as well. The analyses were made according to the theoretical perspective of the Discourse Analysis, emphasizing its utterance aspects and privileging the study of linguistic marks indicating the formation of a group and its specific, reciprocal way of uttering that constitute a certain discursive practice.

Keywords: Slaughterhouse industry workers. Meanings of work. Utterance-based Discourse Analysis. Discursive practice.

\section{Notas}

1 Os seis quadros presentes no artigo foram elaborados pelas autoras.

2 Agradecemos a sugestão do parecerista para que observássemos, em pesquisas futuras, de que modo o trabalhador faz a gestão desse ambiente de trabalho que se impõe; de que modo ele o renormaliza a partir daquilo que enuncia.

Aqui também agradecemos ao parecerista que destacou uma dimensão das dramáticas de uso do corpo-si, que pode ser explorada a partir das SD tanto do Quadro 4 quanto do Quadro 5.

\section{Referências}

BAKHTIN, M. Estética da criação verbal [1979]. São Paulo: Martins Fontes, 2011.

BOSI, A. de P. A recusa do trabalho em frigoríficos no oeste paranaense (1990-2010): a cultura da classe. Diálogos. Revista do Departamento de História e do Programa de Pós-Graduação em História, v. 17, n. 1, 2013. Disponível em: http://periodicos.uem. br/ojs/index.php/Dialogos/article/view/36045. Acesso em: 01 jul. 2019. 
BRASIL. Norma Regulamentadora no 36 - Segurança e saúde no trabalho em empresas de abate e processamento de carnes e derivados (NR-36). Brasília - DF, abril/2013. Disponível em: https://enit.trabalho.gov.br/ portal/images/Arquivos_SST/SST_NR/NR36.pdf. Acesso em: 01 jul. 2019.

BRASIL. Manual de auxílio na interpretação e aplicação da Norma Regulamentadora $\mathrm{n}^{\circ}$ 36: segurança e saúde no trabalho em empresas de abate e processamento de carnes e derivados. Brasília - DF, setembro/2017. Disponível em: https://enit.trabalho.gov.br/portal/images/Arquivos_SST/ SST_Publicacao_e_Manual/CGNOR---MANUĀL-DE-INTERPRETAO-E-APLICAO-DA-NR-36.pdf. Acesso em: 01 jul. 2019.

DAHER, D. C. A entrevista como estratégia metodológica de acesso a saberes sobre a empresa. Ergologia, nº 16, dezembro/2016. Disponível em: http://www.ergologia.org/ uploads/1/1/4/6/11469955/f7._art._2.pdf. Acesso em: 01 jul. 2019.

FORD, H. Minha vida e minha obra [1922] Rio de Janeiro/São Paulo: Companhia Editora Nacional, 1926.

FOUCAULT, M. Vigiar e punir: nascimento das prisões [1975]. Petrópolis: Vozes, 2014.

IKEDO, F.; RUIZ, R. C. Trabalhar e adoecer na agroindústria. Florianópolis: Insular, 2014.

MACHADO, L. F.; MUROFUSE, N. T.; MARTINS, J. T. Vivências de ser trabalhador na agroindústria avícola dos usuários da atenção à saúde mental. Saúde em Debate. Rio de Janeiro, v. 40, n. 110, julho-setembro/2016. Disponível em: http://www.scielo.br/scielo.php?pid=S0103- $11042016000300134 \&$ s cript $=$ sci $_{-}$ abstract\&tlng=pt. Acesso em: 01 jul. 2019.

MAINGUENEAU, D. Novas tendências em Análise do Discurso. Campinas: Pontes, 1993.
MAINGUENEAU, D. Termos-chave da Análise do Discurso. Belo Horizonte: Editora da UFMG, 1998.

MAINGUENEAU, D. Gênese dos discursos. Campinas: Criar, 2005.

MARRA, G. C. Saúde e processo de trabalho em frigoríficos: da necessidade ao adoecimento. Tese (doutorado) - Fundação Oswaldo Cruz, Escola Nacional de Saúde Pública Sérgio Arouca, Rio de Janeiro, 2019.

NOUROUDINE, A. A linguagem: dispositivo revelador da complexidade do trabalho. In: SOUZA-E-SILVA, M. C. Pérez; FAÏTA, D. (org.) Linguagem e trabalho: construção de objetos de análise no Brasil e na França. São Paulo: Cortez, 2002.

PEREIRA, M. C. C. A carne está servida: análise de argumentação jurisdicionais do TST sobre trabalhadores do setor frigorífico na perspectiva gramsciana. Tese Doutorado. Brasília, Universidade de Brasília, 2016. Disponível em: http://repositorio.unb.br/ handle/10482/22170. Acesso em: 01 jul. 2019.

SILVEIRA, A. L. da; MERLO, A. R. C. Superexploração e o processo de adoecimento pelo trabalho na indústria frigorífica de Chapecó/ SC. Revista Grifos no 43, 2017. Disponível em: https://bell.unochapeco.edu.br/revistas/ index.php/grifos/article/view/3768. Acesso em: 01 jul. 2019 .

SOUZA-E-SILVA, M. C. Pérez; FAÏTA, D. (org.) Linguagem e trabalho: construção de objetos de análise no Brasil e na França. São Paulo: Cortez, 2002. 